\title{
INDECISÕES E PROCRASTINAÇÕES: A FUSÃO AT\&T- TIME WARNER E A REGULAÇÃO NO BRASIL
}

\author{
Indecisions And Procrastinations: At \& T-Time Warner Merger And Regulation \\ In Brazil
}

\section{Indecisiones Y Procrastinación: At \& T-Time Warner Fusión Y Regulación En Brasil}

João Martins Ladeira Universidade Federal do Paraná, joaomartinsladeira@gmail.com

\section{Resumo}

Centrado numa perspectiva arqueológica e atento à forma adotada pelas mídias para a constituição do streaming, o texto analisa o julgamento sobre a compra da Time Warner pela AT\&T no Brasil, cujo resultado permitirá a criação de novas plataformas de difusão para a imagem mediante a associação entre uma estrutura para tráfego de informação e o conteúdo de um criador global. Ainda indefinido, o processo se estende desde 2017, em meio a deliberações legais divergentes, que, contraditoriamente, põem em questão a própria norma que avalia o caso. No Brasil, seus termos se tornam parte do que é discutido, expondo uma relação repetida com as normas. Tal dúvida envolve intervenções que buscam produzir dos reguladores uma interpretação das leis segundo as expectativas de quem é julgado, numa decisão com força para inviabilizar um evento capaz de renovar a difusão do audiovisual.

Palavras-chave:. Estudos de Televisão. Arqueologia da Mídia. Streaming

\begin{abstract}
Oriented by an archeological perspective, this text analyzes the judgment about the acquisition in Brazil of Time Warner by AT\&T, whose outcome will allow the creation of new platforms to image diffusion due to the association between a specific structure for information traffic and the resources of a global content creator. In a process relevant to the definition of the media form adopted in the constitution of streaming, the case since 2017 remains undefined, in divergent legal deliberations, which, contradictorily, brings to question the norm that evaluates the judgment. The law becomes part of what is discussed, exposing a repeated relationship with the norms. This doubt regards interventions that try to produce an interpretation of the law by the regulators which is compatible with the expectations of whom is being jugged, in an event able of renovating audiovisual diffusion.
\end{abstract}

Key words: Television Studies. Archeology of Media. Streaming.

\section{Resumen}

Centrado en una perspectiva arqueológica, el texto analiza el juicio sobre la adquisición de Time Warner por AT\&T en Brasil, cuyo resultado permitirá la creación de nuevas plataformas de difusión de imágenes al asociar una estructura de tráfico de información con el 
contenido de un creador global. Proceso relevante para definir la forma en que los medios deben adoptar para la constitución de la transmisión, el caso aún no está definido, extendiéndose desde 2017 en medio de deliberaciones legales divergentes, que cuestionan contradictoriamente la norma que evalúa el caso. Los términos de la ley se convierten en parte de lo que se discute, exponiendo una relación repetida con las normas. Dicha duda involucra intervenciones que buscan producir de los reguladores una interpretación de las leyes de acuerdo con las expectativas de aquellos que son juzgados, en una fuerte decisión de prevenir un evento capaz de renovar la difusión del audiovisual.

Palabras clave: Palabra clave. Palabra clave. Palabra clave.

\section{INTRODUÇÃO}

Quando, em 2011, o Congresso Nacional finalmente aprovou o SeAC (Lei do Serviço de Acesso Condicionado, $n^{\circ}$ 12.485), a televisão segmentada no Brasil parecia ter encontrado uma solução provisória, embora eficiente, para o equilíbrio forças entre os criadores nacionais de conteúdo e os serviços de tráfego de dados: ou seja, as corporações de telecomunicações ibero-americanas então em ação no Brasil. Como toda solução contingencial, parecia inevitável que cedo ou tarde ela se desgastasse, e a transposição do audiovisual para a internet, junto à crescente importância das plataformas de streaming, acelerou esta erosão muito rapidamente. De súbito, tal harmonia forçada se viu exposta à intervenção de empreendimentos sem qualquer reserva em relação às articulações prévias para o território nacional.

Oportunidade ímpar para observar esta recomposição tem sido as aquisições globais entre as estruturas ainda mais amplas para a difusão de dados e os produtores de conteúdo essenciais. Caso relevante se torna a compra da Time Warner pela AT\&T em 2016, cujo objetivo é permitir a expansão de serviços on-line de audiovisual já existentes e a criação de outros inéditos. Algo semelhante esteve contido na aquisição da NBC pela Comcast em 2009, por exemplo; porém, os efeitos de agora se mostram mais intensos. Hoje, estão em pauta as transformações inscritas no streaming, quando os criadores buscam transpor seu conteúdo para aplicativos e os agregadores procuram negociar emissoras em separado, diluindo restrições previamente impostas (KEATING, 2012; LOTZ, 2014; WOLK, 2015).

Neste instante, a imagem se arrisca a tornar-se um recurso gerenciado por corporações de tráfego de dados. Tal formato implica uma intensa concentração, contendo o risco de produzir a mais séria contraposição a princípios importantes para a internet (WU, 2012). As dificuldades impostas à difusão segundo o formato aberto característico a web pode transformar o audiovisual num recurso prioritário de algumas redes, numa renovação perversa 
da imagem. Esta discussão atravessa também o Brasil, mas o tratamento dado aqui ao caso AT\&T-Time Warner tem sido bem mais restrito. Em nosso país, a atenção se debruçou sobre as dificuldades desta aquisição frente às barreiras à propriedade cruzada impostas pelo SeAC, relevantes para um círculo restrito de operações nacionais, e que esbarram agora em interações muito mais extensas.

O SeAC proíbe que um serviço de tráfego (como a AT\&T) possua uma empresa de conteúdo (como a Time Warner). Segundo seus art. $5^{\circ}$ e $6^{\circ}$, criadores não podem ter mais de $50 \%$ de operações de telecomunicações. Por sua vez, estas corporações de dados não devem possuir mais de $30 \%$ dos produtores, deparando-se também com o impedimento em deter direitos sobre audiovisual. Compreender o sentido de um tratamento preso a problemas tão intestinos torna-se o objetivo deste artigo.

Interpreta-se esta posição como o efeito de uma estratégia para a manutenção de poder por certos grupos nacionais, frente a uma reorganização na qual se mostram incapazes de participar, mas em que não abrem mão de intervir. A teoria utilizada é a arqueologia da mídia (HUHTAMO; PARIKKA, 2011; PARIKKA, 2012), com atenção às múltiplas esferas para a constituição dos meios. Aqui, interessa uma delas: a dimensão jurídica indispensável a qualquer fusão, dado o poder que dispõe para impor restrições à forma das mídias. Nestes momentos, as normas possuem uma influência incomum, e sua análise permite apreender os embates presentes na reconstituição dos meios.

A investigação se volta para as relações de poder em curso, numa reação local a intensos fluxos globais, apropriando-se de certas contradições inscritas nas normas a fim de acionar as oportunidades contidas em sedimentações impostas por decisões pregressas. Uma avaliação legal pode barrar tais compras, impor barreiras, introduzir dificuldades que façam com que o acordo se arraste por muito tempo. Todos estes instrumentos serão utilizados durante o caso AT\&T-Time Warner. Como hipótese, propõe-se que estas indecisões recuperam certas dinâmicas recorrentes para lidar com as normas durante as discussões brasileiras sobre o audiovisual, misturando futuro e passado.

Não é primeira vez que certos personagens se apropriaram de normas, e o SeAC havia sido criado segundo certos interesses específicos. Que esta tendência novamente se repita, especialmente num momento de intensa transformação, justifica a importância de compreender em que termos se exerce tal tipo de poder. O SeAC continha cláusulas de segurança que impediam a expansão da importância, no audiovisual brasileiro, de corporações de tráfego de dados (LADEIRA, 2016). Restrição criada a fim de privilegiar criadores 
nacionais de conteúdo, torna-se um mecanismo repetidamente acionado nesta fusão, levando a lei a seu próprio limite.

Este artigo se divide da seguinte forma. A primeira parte aborda questões conceituais. Como parte de uma visada voltada a compreender a constituição do streaming a partir dos estudos de televisão, busca-se apreender esta integração da imagem em contraponto a outras formas previamente constituídas: o multicanal (a televisão segmentada) e o broadcast (as redes nacionais generalistas de televisão). Define-se essa ideia de "forma" seguindo a leitura de Deleuze (1986) sobre Foucault $(1969,1975)$, visando à compreensão de uma dimensão que concede caráter constitutivo à realidade (MASSUMI, 1992). Numa abordagem arqueológica, compreende-se tal resultado como consequência de fatores multidimensionais (ZIELINSKI, 1994), envolvendo dimensões econômicas, jurídicas e técnicas, cada uma delas com uma influência pontual.

O esforço permite compreender a repetição de certos traços como consequência das estratégias de poder. A principal delas se torna a tentativa de recuperar neste evento uma contradição presente no próprio SeAC, que, criado para resguardar certos benefícios, introduz uma tensão possível de retornar em outro contexto. A imprecisão que se busca atribuir à norma permite uma confusão curiosa: durante a deliberação desta fusão específica, põe-se em dúvida a própria lei a partir da qual se deveria julgar a operação AT\&T-Time Warner, invertendo-se a ordem sobre quem avalia o quê. Agora, depara-se com um embate no qual o próprio SeAC se encontra em questão, num julgamento em que, ao contrário, as decisões deveriam nele se basear.

Esta circunstância ilustra um reequilíbrio de forças em meio a certas transformações, nas quais se tenta arrancar a fórceps os benefícios inscritos em tal lei. Este enquadramento conduz à segunda parte do texto. Nele, encara-se a problemática central contida na análise sobre o caso AT\&T-Time Warner no Brasil, utilizando-se como material empírico das deliberações produzidas pelas agências reguladoras e pelo órgão para a defesa de concorrência, instâncias com a autoridade para tomar decisões de impacto duradouro. Esta escolha se justifica devido à influência destes documentos nos resultados da fusão, pois tais deliberações contêm o poder de delimitar o formato que tal mídia virá a ter.

Tais discussões envolvem uma intensa incerteza sobre como lidar com o SeAC, numa relação com a lei pautada pelo esforço de dela passar ao largo. A defesa segue esta direção, e - mais curioso - também o órgão regulador, adotando uma postura que restringe seu poder de intervenção. Ocorre então uma colisão entre duas interpretações apresentadas pela própria 
agência setorial, indicando direções distintas para o caso. A terceira parte do texto se debruça sobre a outra alternativa para lidar com a SeAC, que surge das intervenções dos demais envolvidos nesse evento: a Abratel (Associação Brasileira de Rádio e Televisão) e a Abert (Associação Brasileira de Emissoras de Rádio e Televisão), cujos argumentos terminam por interferir nas atribuições dos reguladores, outorgando a eles ações que não lhes cabem, como modo de alcançar objetivos que contrariam às próprias normas.

Esta análise buscar tornar visível como vem a ser reapropriada uma norma construída para sanar tensões entre personagens que encontraram, na tramitação da lei, um meio de equilibrar os seus interesses, elaborando uma norma capaz de se adequar a expectativas contingenciais. Busca-se compreender esta tensão como um traço patrimonial, elucidando a tendência de apropriar certos instrumentos segundo expectativas particulares. No momento em que se finaliza a redação deste texto, este caso ainda se encontra sem solução: a despeito de manifestações intermediárias, as entidades regulatórias se pronunciaram sobre o caso, mas não em definitivo. $\mathrm{O}$ resultado futuro poderá introduzir consequências significativas para o audiovisual no Brasil, e o debate acadêmico sobre o caso deve ocorrer desde já.

\section{Uma visada arqueológica sobre as normas}

Parte dos estudos de televisão se concentrou na análise dos conteúdos desse meio. Contribuições valiosas permitiram apreender como o audiovisual mediava os traços do cotidiano (MARTÍN-BARBERO, 1998). Outras, debateram sua qualidade estética a partir de uma definição sobre as especificidades de tal mídia (MACHADO, 2000). Certas perspectivas se debruçaram sobre a abertura dos formatos convencionais do audiovisual em direção a conexões variadas, até então inexploradas (MITTELL, 2015). Uma questão que complementa tais discussões sobre conteúdo reside num debate relativo à ordenação do próprio meio, na expectativa de compreender como, em cada momento, suas características materiais se constituíram (ZIELINSKI, 1994).

A discussão aqui proposta debruça-se sobre tal processo, entendendo cada resultado obtido para a formalização de uma mídia como o efeito das dinâmicas relevantes na constituição da própria realidade. Compreende-se a formalização dos meios tematizando a operação de esferas distintas e autônomas, inspirando-se no conceito de contradição sobredeterminada, invocado por Hall (2003) a partir de sua leitura particular de Althusser (1965). Uma dessas esferas são as normas jurídicas. A atenção a elas não significa propor sua 
prevalência sobre as instâncias das trocas ou das técnicas, mas apenas de uma opção nesse momento mais apropriada frente a outras dimensões.

Esta ênfase em instâncias dissociadas envolvidas na organização da história distanciase da suposta progressão de eventos, cuja coordenação levaria a algum resultado supostamente mais avançado em relação ao anterior. Em contraponto, surge uma atenção a dinâmicas coordenadas, produzindo efeitos devido à relação entre as partes. As leis se tornam uma particularidade influente. Importa pensar a articulações que ocorrem nessa instância, numa investigação sobre aquilo que será constituído através de relações de poder, marcadas pela repetição e pela recorrência típica a um fenômeno consolidado.

Tal poder deve ser entendido não como uma atribuição concentrada numa instituição centralizadora, determinando as outras instâncias. Importa a especificidade de cada segmento na reprodução da vida social, com ênfase nas suas singularidades. Abandona-se certa imagem piramidal, investindo nos muitos elos possíveis. Atenta-se à constante retomada de certos traços, na expectativa de compreender como se dá esta repetição. Tal recorrência opera através de singularidades, conectando múltiplos pontos, numa associação capaz de lhes oferecer unidade (DELEUZE, 1986).

Esse artigo se depara com a retomada de uma estratégia que, pelo poder, outorga outra vida a traços patrimoniais, exatamente quando algumas forças pareciam hoje menos importantes que no passado. Parte desta repetição se deve a certas características inscritas no SeAC. Se as soluções idiossincráticas construídas para a avaliação do acordo AT\&T-Time Warner buscam se apropriar da normatização abstrata em benefício de interesses particulares, isto decorre de brechas construídas durante a criação desta lei. São tensões contidas na sua constituição. A norma tramitou no período em que começava a se mostrar importante contar com os serviços de telecomunicações como fonte de investimento para a televisão segmentada, enquanto se tornava igualmente relevante evitar sua participação indesejável no audiovisual brasileiro (POSSEBON, 2016).

Noutros instantes, essas mesmas estratégias serviram para renovar o poder de certos personagens $^{1}$. Agora, barreiras solidificadas são postas em dúvida. Solução frágil, o SeAC

\footnotetext{
1 Um exemplo: de caráter limitado e transitório, que se relacionava mal com as normas para o cabo posteriormente implantadas e que não dizia respeito aos serviços segmentados já em operação desde os anos 70 , a primeira regra no Brasil para um tipo muito particular de transmissão paga (o Decreto 95.744, de 23 de fevereiro de 1988) foi criada de modo a permitir a Abril realizar seu projeto para explorar a televisão segmentada. Dava ao grupo o uso esperado a uma outorga para UFH obtida por ele em 1985 na cidade de São Paulo, recebida num diálogo muito próximo com a Presidência da República e o Ministério das Comunicações. A criação desta outra legislação se deve à impossibilidade da Abril em vender o acesso ao canal devido a
} 
conciliava interesses cuja manutenção dependia de certa tolerância por parte daqueles que ainda não haviam se interessado em entrar num conflito aberto com quem ainda detinha uma influência em notável dissolução. Esse caso aponta para uma revisão de tal equilíbrio, com criadores de conteúdo enfraquecidos, embora ainda capazes de intervenção. Novos envolvidos tentam se afirmar, e eles demonstram pouco interesse em considerar os interesses daqueles que participam de longa data no audiovisual brasileiro.

Porém, os métodos que encontram para afirmar sua influência recuperam as mesmas estratégias de poder, num indício de sua resiliência. A apropriação particular das normas envolve um emaranhado de interações. Algumas delas partem do endosso sobre certas interpretações desta lei pelos próprios órgãos reguladores. Outras, lidam com a leitura do texto a partir da perspectiva daqueles que mais poderiam perder com o seu abandono. A análise pontual do caso se dá na próxima seção.

\section{Imbróglios jurídicos: Cade e Anatel em posições contrapostas}

Anunciada nos EUA em 10/2016, a compra da Time Warner pela AT\&T por US\$ 85,4 bilhões aponta desde o início para o futuro. Representa a tentativa da operadora de infraestrutura em utilizar tal conteúdo em suas redes móveis, prevendo sua crescente relevância na difusão do audiovisual. Desta perspectiva, os dispositivos portáteis alimentados por tecnologias de comunicação sem fio se tornariam o local privilegiado para acesso à imagem (AT\&T, 2016). A concentração entre ambas as operações deixaria de lado os acordos usuais de licenciamento, concedendo a AT\&T um intenso poder sobre conteúdo. A exclusividade permitiria introduzir rapidamente novos produtos, repetindo estratégias de corporações como a Apple para administrar suas inovações (VOGELSTEIN, 2013).

A propriedade unificada envolve uma circulação de material que permite um tráfego sem limites para o audiovisual, radicalizando a lógica do protocolo (GALLOWAY, 2004). A imagem poderia circular entre equipamentos conectados, administrados por provedores de infraestrutura dispondo dela com liberdade. O formato dá prosseguimento a maior proximidade entre audiovisual e operações de telecomunicações, principais envolvidos na construção de estruturas para tráfego às quais a difusão de conteúdo se atrela. Progressivamente, certos criadores se transformam num anexo destes serviços, alimentando

barreiras contidas na lei de radiodifusão, tecnicidade sanada por essa outra norma de 1988. Trata-se de uma decisão legal adequada a um projeto individual (POSSEBON, 2009). 
tais redes e despertando receios sobre a construção de canais exclusivos para o audiovisual (WU, 2012).

No Brasil, esta expectativa envolve uma complexidade particular, consequência do choque entre tal reorganização global e os limites inscritos no SeAC à propriedade cruzada. Em 05/2014, a AT\&T havia adquirido a DirecTV, passando a controlar esta operação de satélite na América Latina, assim como a sua filial brasileira, a Sky (MERCED; GELLES, 2014). Esta decisão dá início a um longo embate legal, permeado pela recorrente tendência dos personagens locais em buscar caminhos para resguardar uma importância em constante erosão frente a transformações mais extensas.

Questão chave se torna a dúvida sobre como lidar com o SeAC. A preocupação repercute em quase todos os momentos, e diversos personagens se envolverão na definição sobre o rumo a tomar, tenham eles ou não autoridade para tal. Em 03/2017, a compra é encaminhada ao Cade (Conselho Administrativo de Defesa Econômica), que, seguindo os procedimentos usuais, comunica-se em 04/2017 com a Ancine (Agência Nacional do Cinema) e a Anatel (Agência Nacional de Telecomunicações), a fim de ambas se pronunciarem sobre a regulação setorial. O Cade consiste num órgão de defesa da concorrência, e a sua avaliação sobre o caso volta-se apenas a questões de competição. Parecia claro que ambas as agências regulatórias se definiam como as entidades legítimas para se pronunciar sobre o SeAC.

Porém, as discussões legais posteriores versarão exatamente sobre as atribuições dos envolvidos no caso. As primeiras deliberações das agências reguladoras sobre o SeAC se dão entre 04/2016 e 05/2017, período no qual a Anatel produz dois documentos: o "Informe $\mathrm{n}^{\mathrm{o}}$ 15", emitido pela Superintendência de Competição, e o "Parecer n $\mathrm{n}^{\mathrm{O}} 302$ ", apresentado pela Procuradoria Especializada. O último texto será a "Nota Técnica n ${ }^{\circ}$ 3" da Superintendência de Análise de Mercado da Ancine (2017) ${ }^{2}$. Esses documentos apresentam um emaranhado de problemas, com posições bem distintas entre si, tornando claras as tensões intrínsecas a uma norma dúbia.

Dois tópicos vêm à pauta. $\mathrm{O}$ primeiro se refere aos possíveis riscos concorrenciais da fusão AT\&T-Time Warner. Consiste numa preocupação presente em qualquer aquisição, tratada em decisões do Cade. $\mathrm{O}$ segundo diz respeito à regulação, e traz à tona a força dos limites inscritos no SeAC. Essa outra decisão compete a Anatel, mas o cerne do caso reside na atribuição de tarefas decisórias: ponto central, porém, aberto ao debate.

\footnotetext{
${ }^{2}$ Documento profundamente crítico em relação à operação, seu conteúdo não difere muito das avaliações do Cade. Contudo, possui um tom mais agressivo e uma conclusão bastante enfática: exige que se impeça o acordo. Por razões de escopo, este texto se concentra apenas nas contradições entre Anatel e Cade.
} 
Elaborado pela divisão técnica da Anatel, o "Informe n ${ }^{\circ} 15$ " descartava, por um lado, a necessidade de anuência prévia, exigência que não caberia neste acordo. Agora, o tema se mostra mais inócuo do que se revela depois, ao servir de instrumento para uma discussão polêmica tratada mais adiante. Por outro lado, surge a questão decisiva para a compra: a autoridade da própria Anatel sobre a autorização e, através deste questionamento, uma discussão sobre a própria regulação. Problematizar estas atribuições permite inverter os termos da lei, introduzindo uma dubiedade imprevisível no processo (ANATEL, 2017a).

O documento repete posturas adotadas pela própria defesa da Time Warner. O Informe define este criador como uma operação sem atividade direta no Brasil, interpretação com implicações severas sobre a autoridade do SeAC e da própria Anatel. Segundo o órgão, tal corporação consistiria num empreendimento sediado nos EUA, voltado, em nosso país, apenas a licenciamento e negociação de conteúdo. Entre nós, a Time Warner não poderia ser compreendida como um produtor de audiovisual. Se realiza esta atividade, o faz alhures, e não no território brasileiro. Aqui - neste espaço onde valem as leis locais - ocorreria apenas a programação de certas emissoras e a distribuição de conteúdo em plataformas diversas.

Ao se atribuir a Time Warner uma importância tão restrita, torna-se difícil aplicar as restrições do SeAC. Tal caracterização descarta as barreiras erguidas pela norma, assim como a autoridade dos órgãos reguladores. Suas restrições recairiam somente sobre corporações brasileiras, e apenas seus atos deveriam ser administrados. Seria como se os limites à propriedade cruzada não dissessem respeito a empreendimentos globais. Se a regra versava somente sobre corporações com sede aqui, e - mais importante - se tal localização não era coisa definida a princípio e se encontrava aberta à discussão, o SeAC não poderia ser aplicado sem complicações.

Contudo, esse se revela somente parte do problema. O "Informe $\mathrm{n}^{\circ} 15$ " também reparte as atribuições do SeAC, retomando outra decisão prévia: aquela tomada em 2012 sobre as relações entre a Globo (outro produtor de conteúdo) e a Net (mais uma empresa de telecomunicações). Aquela outra deliberação torna-se agora bastante útil. A associação entre a Globo e a Net fora então analisada em partes distintas. Na ocasião, a Anatel entendeu que a sua própria competência se limitava apenas a empreendimentos de infraestrutura. Logo, restringiu sua deliberação à empresa de telecomunicações, metade da questão. Tópicos que versavam sobre conteúdo foram averiguados pelo outro personagem que lida com o setor, a Ancine (LADEIRA, 2016). 
Em 2017, a menção àquele outro caso é breve, mas decisiva, assegurando uma alternativa viável de adicionar às deliberações legais futuras. Como ocorreu anos antes, se poderia supor que, frente a um resultado desfavorável aos envolvidos, um tema como esse imbróglio geográfico poderia ser averiguado por uma segunda agência. No caso GloboTelmex, esta solução resguardou a participação do criador nacional na operação de infraestrutura (uma barreira proibida pelo SeAC), num resultado obtido graças ao entendimento da Ancine sobre controle decisório, mais frouxo frente àquele mantido pela Anatel. Quando as concepções de um regulador deixam de servir, não parece difícil recorrer a outro, em busca de uma deliberação adequada às expectativas de quem é julgado.

Agora, reafirma-se a ideia de que o audiovisual brasileiro comporta dois órgãos aptos a decidir sobre uma mesma questão. Ao recuperar a separação atribuída ao SeAC, o "Informe $\mathrm{n}^{\mathrm{o}} 15$ " sugere que tal argumento estará disponível sempre que se mostrar conveniente. Pois, mais uma vez, uma agência vai deliberar sobre apenas parte do setor. No caso Globo-Net, estava em jogo compatibilizar a influência que a operação de broadcast mais importante do Brasil desejava manter com tal operação de infraestrutura, da qual ainda não tinha se desvinculado nem pretendia fazê-lo. Para a associação entre a AT\&T e a Time Warner, o instrumento será o mesmo: a separação das deliberações em termos de infraestrutura e conteúdo. Contudo, os efeitos se mostram diversos, pois tal caso se refere à condição do Brasil frente a reordenações mais profundas.

Tal informe era apenas parte da análise. A ele se atrela a posição da Procuradoria Especializada da Anatel, órgão jurídico ligado à AGU (Advocacia-Geral da União). Esta segunda manifestação ocorre em outro texto, o "Parecer no 302", com uma interpretação bem diferente sobre o acordo. Seu conteúdo se contrapõe ao documento pregresso, contestando quase todos os itens anteriormente discutidos, divergência que resume o caso em extremos (ANATEL, 2017b; ANCINE, 2012). O "Parecer $\mathrm{n}^{\circ}$ 302" revê a interpretação sobre a localização da Time Warner. Contestando a postura defendida pela outra instância, considera difícil tratar este criador do modo anteriormente apresentado. Como esperado, recorre ao SeAC, agora com foco em seu art. $9^{\circ}$, cujo texto afirmava que apenas empresas em operação no Brasil poderiam realizar atividades de programação.

Dito de outro modo, recuperava-se esta norma na expectativa de propor que, ao se exercer no Brasil um serviço de programação, não caberia argumentar sobre uma sede localizada alhures. Evidências citadas vão ser a listagem das CNAEs (Classificação Nacional de Atividades Econômicas) das subsidiárias brasileiras da Time Warner. Pretende-se inferir 
suas atribuições, pois - segundo o próprio texto - a Anatel não dispunha de informações detalhadas sobre os serviços prestados por tais empreendimentos. Ênfase pontual recai na classificação 59.11-1-99, que diz respeito exatamente a "estúdios cinematográficos", invalidando, segundo o documento, a tese sobre a ausência de trabalho criativo. Esta classificação retoma o embate do ponto que havia parado: o art. 5 do SeAC, que versa sobre propriedade cruzada.

Mas a geografia representa somente metade do problema. Outra fração estava em definir a autoridade a se atribuir a Ancine, agência indicada como responsável por deliberar sobre o conteúdo. Se, de fato, tal assunto estava sob sua alçada, a compreensão do órgão sobre suas próprias normatizações se torna um tema a observar. Recorre-se aos documentos desta segunda agência produzidos durante a regulamentação do SeAC. Cita-se a "Instrução Normativa $n^{\circ} 102 / 2012$ ”, determinando o imperativo de obedecer às normas brasileiras no que diz respeito à responsabilidade por responder judicialmente e ao poder de realizar contratos.

Esta "Instrução no 102" era uma forma de lidar com a globalização do audiovisual. Como boa parte do conteúdo em circulação no nosso país consiste de material produzido em outras regiões, tornava-se necessário elaborar meios para, aqui, administrar esses recursos. Em 2017, a Procuradoria Especializada recupera um caráter muito específico ao setor: a forma como a atividade desconsidera fronteiras nacionais. Segundo tal texto, embora tais atividades fossem exercidas por corporações internacionais, era obrigatório considerar os parâmetros do órgão nacional de regulação, orientados, por sua vez, pelo SeAC. Trata-se de um esforço para fazer valer a norma; que, supõe-se, deveria ser indiscutível.

Ao fim desta contraposição, o "Informe $\mathrm{n}^{\mathrm{o}} 15$ " teria se tornado um parêntese divertido, talvez curioso - ilustrando as contradições internas de um mesmo órgão. Os entendimentos apontam para duas decisões contrárias, e, seguindo os procedimentos técnicos, a solução precisaria ser posteriormente tomada pelo Conselho Diretor da Anatel. Como se esta tensão não bastasse, presencia-se ainda outra interferência no caso, que, introduzida pela Abert, traria à tona o tema supostamente menor da anuência prévia, provando que nestes assuntos qualquer recurso pode ser utilizado.

\section{As manifestações da Abert}

Nesse caso, certos resultados decorrem de demandas que, a despeito de seu conteúdo duvidoso, terminam produzido resultados influentes. Recorrendo ao SeAC na busca por adaptá-lo às suas expectativas, a Abert termina por exigir de algumas organizações atos 
distintos de suas competências. Estas demandas garantirão que a fusão permaneça pendente mesmo depois de aprovada pelo Cade. Um pedido da Associação leva a uma decisão intermediária da Anatel, prévia à conclusão de sua análise, como uma posição provisória, capaz de permitir uma indecisão estável. Tal resultado importa não apenas pelo seu conteúdo, mas também por sua forma.

Em 05/2017, o Cade aceita as partes interessadas na operação, empreendimentos não diretamente envolvidos no julgamento, mas que ganham o direito de acompanhá-lo. Apresentam solicitações o Simba (agrupamento entre SBT, Record e RedeTV! para a negociação de sinal junto a operadoras segmentadas) e a NeoTV (associação que reúne cerca de 130 serviços de multicanal, além de empresas de internet, emissoras e fabricantes de equipamentos). Acata-se também um pedido da Fox, da ESPN e da Discovery, serviços globais de conteúdo cujo envolvimento se justifica devido à venda de material para a Sky; e, no caso da Fox, graças também à sua difusão desagregada de audiovisual por aplicativos, distinto do padrão típico ao multicanal (BERBERT, 2017a).

Entre as associações brasileiras que reúnem empreendimentos de audiovisual aptas a se apresentar estão a Abratel (cujo pedido é negado devido a uma solicitação fora do prazo) e a Abert. Esta última, embora não tenha se apresentado segundo os procedimentos formais, se mostra um dos personagens mais vociferantes. Seu envolvimento se inicia em 04/2017, antes mesmo de todas as formalidades processuais. Em suas intervenções, recorre a quase todas as autoridades disponíveis. Em busca de um meio para evitar a aquisição, repete a tendência de, sempre que possível, evitar a expansão da relevância de outros criadores no Brasil. Importam não apenas seus atos: relevante se torna sua relação com as normas (ABERT, 2017a).

A Abert demanda ao Cade que chame para si a autoridade sobre questões regulatórias, o que não lhe compete, do mesmo modo que pede a Anatel que evite a coordenação de ações entre AT\&T e Time Warner antes da decisão final pela Agência. Em julgamentos deste tipo, as aprovações do Cade vêm acompanhadas de certas restrições, limitando a fusão sem impedila. A decisão da Anatel por descartar a anuência prévia eliminou uma das poucas oportunidades, caras a Abert, de evitar integralmente a operação. Ao deixar de lado esta etapa, o caso seguia para o Conselho, que, embora concentre uma autoridade significativa sobre a compra, ingere apenas sobre temas de concorrência. A próxima chance para barrar a operação surge apenas na avaliação setorial da Agência, que ocorre após a decisão do Cade, e, consequentemente, depois da finalização da compra. 
Apresentada entre 06/2017 e 08/2017, a demanda se baseia em tecnicalidades. Uma vez que o caso prescindia de anuência prévia, solicitava-se ao Cade que interrompesse a operação através da barreira regulatória inscrita no SeAC, embora isso consista num poder restrito à Anatel. A Abert demanda ao Conselho, órgão centrado apenas na análise de concorrência, um pronunciamento regulatório, relativo à proibição da propriedade cruzada. Pressupõe que a atribuição, estranha ao Cade, deveria ser por ele executada devido à suposta incapacidade da Agência em exercer tal tarefa. A atribuição deste poder ao Conselho se justificaria - diz-se - porque a separação entre telecomunicações e conteúdo inscrita no SeAC consistiria num instrumento para garantir a concorrência (ABERT, 2017b).

São esforços significativos para fazer essas instituições de comportarem da maneira mais adequada às expectativas da associação que representa os criadores de conteúdo, aqueles envolvidos de longa data com o audiovisual no Brasil que, em sua trajetória, entenderam as normas como algo sempre possível de apropriar segundo seus interesses. Tais demandas ilustram como tais personagem esperavam que a regulação se comportasse: segundo um cenário condizente com suas expectativas. Agora, o resultado seria distinto de circunstâncias anteriores, embora não se deixe de resguardar uma posição vantajosa: a barreira instituída pela Anatel, impedindo a coordenação entre Sky e Time Warner no Brasil.

O Cade se pronuncia em 07/2017, negando as exigências da Abert (CADE, 2017). O Conselho defende a autoridade das agências reguladoras, excluindo de suas atribuições temas alheios à dimensão econômica. Esta posição insiste nas compensações impostas pela análise de concorrência, atribuição do Conselho. Atém-se ao caráter universal das normas, contrapondo-se à particularidade contida nos argumentos da Abert. Segundo o Cade, debruçar-se sobre a regulação obrigaria o Conselho a considerar as diversas particularidades de todos os segmentos com que lida. Afinal, cada uma destas especificidades poderia ter impactos sobre a concorrência. Caso fosse obrigado a agir assim em cada operação sobre a qual se debruça, suas atribuições teriam uma amplitude incomensurável.

A Abert recorre ao Cade ainda que - na verdade, exatamente porque - tal ato ignora a lógica dos procedimentos, numa tentativa de se apropriar do caráter binário do SeAC. Quando em certo instante as agências reguladoras não possuem o poder para realizar as vontades de quem pede, solicita-se a certo órgão que faça valer uma atribuição que cabe a outro. Pior para as normas se, embora a Anatel exerça a autoridade sobre uma atribuição a se decidir no futuro, falte-lhe agora a autoridade para interromper uma compra. 
Tal discussão parecia encerrada. Porém, frente à negativa sobre uma análise do Cade sobre propriedade cruzada, em 07/2017 a Abert (agora junto a Abratel) pede a Anatel que se pronuncie antes do Conselho. Alegam que esperar pela aprovação consumaria os riscos à lei, pois a Agência agiria quando a norma já tivesse sido quebrada. A Anatel negaria o pedido em 08/2017, mas a derrota das duas associações não seria completa. Em sua resposta, a Agência aprova uma medida cautelar impedindo as operações entre Sky e Time Warner e evitando qualquer transformação em sua organização (BERBERT, 2017b).

A despeito de manter a agenda para suas deliberações, a Anatel não deixa de atender parcialmente às demandas das associações. Afirma-se a ordem de tramitação legal, minimizando a negativa. Contudo, ao menos uma parte dessas expectativas particulares se concretiza (BERBERT, 2017c). Após tal limitar, qualquer expectativa de integrar o tráfego de dados com o material de tal criador, motivo do acordo global, via-se no Brasil excluído do horizonte: se é que aqui havia essa expectativa...

A aprovação pelo Cade, que ocorre em 10/2017, reafirma a posição de não se pronunciar sobre o SeAC. Declara que a regulação setorial ficaria sob responsabilidade da Anatel e da Ancine e assume a complementaridade em tais decisões. Preocupação essencial se torna resguardar outra análise do acordo frente ao risco de uma negativa durante a discussão regulatória. Para isso, o Acordo em Controle de Concentração (AAC) celebrado entre as corporações e o Cade, com prazo de cinco anos e previsão de multas a partir de $\mathrm{R} \$ 10$ milhões, implica o compromisso dos envolvidos de evitar prejuízos na venda de conteúdo ou na distribuição de canais, especialmente para empreendimentos de menor porte. O mecanismo garante também a probabilidade de se reverter a compra. São decisões em relação ao futuro: o Conselho garante uma nova avaliação caso o acordo não venha a se concretizar devido à avaliação a ser tomada pelos reguladores (BERBERT, 2017d).

A Anatel esperava iniciar suas deliberações após a decisão do Cade, embora, ao mesmo tempo, decida aguardar pela definição do caso nos EUA. Lá, o julgamento seria finalizado em 06/2018, numa solução bastante instável. Embora o Departamento de Justiça não tenha recomendado a compra, a aquisição termina aprovada pela decisão de um juiz do Tribunal de Distrito dos Estados Unidos em Washington (LEE; KANG, 2018). No Brasil, as discussões seriam então reabertas. Porém, após essa longa deliberação, o caso volta à fase de instrução por parte das agências regulatórias. As decisões poderiam ser revistas, supondo a dúvida sobre a manutenção das posições anteriores. Até a redação final deste texto, o caso se encontrava em suspenso, num indício da indecisão que paira sobre nosso país. 


\section{Conclusão}

No audiovisual brasileiro, as forças em confronto são outras, sem que se possa pode dizer que envolvidos de longa data com esse segmento tenham perdido capacidade de influência. Exercem-na quando se encontram mais fracos do que outrora - na verdade, exatamente por isso. Conforme sua importância se reduz, resguardam uma influência que não hesitam em utilizar, com efeitos nada desprezíveis. Isso envolve vieses da própria norma, na qual se introduziu temas contraditórios a fim de acomodar interesses do passado, dos quais agora não se pode esquivar. Ao longo do debate, consente-se que o SeAC está velho e precisa ser mudado - contraditoriamente - quando se analisa uma aquisição que tal norma poderia inviabilizar.

Tais dubiedades se mostram recorrentes nas discussões jurídicas sobre o audiovisual no Brasil, e os traços aqui analisados remetem a uma tendência ampla. A discussão legal sobre um acordo essencial para a reconfiguração do audiovisual se concentra num mecanismo útil na conciliação dos interesses de outrora. Que se deixe de abordar preocupações mais amplas, como as de neutralidade de rede, indica o caráter limitado da avaliação. Arranjos relevantes apenas para aqueles capazes de apropriar benefícios pontuais encontram ressonância devido a uma tendência de subordinar instrumentos técnicos a expectativas particulares. No Brasil, tal análise versa menos sobre o caso, e mais sobre o SeAC, na tentativa de se apossar das oportunidades nele disponíveis.

Nada disso é inédito, como um déjà vu de embates pregressos sobre a televisão. Essa retomada indica a resiliência de certas formulações para o poder, centrado no uso de especificidades legais que, a fim de garantir a influência de certos envolvidos, apresentam o embate como a execução de parâmetros jurídicos abstratos. Tais esforços para fazer valer dadas expectativas envolvem um imbróglio sobre a relação entre o Cade e a Anatel, atribuindo a essas instituições as responsabilidades que se gostaria de ver desempenhadas conforme os resultados se aproximem mais das solicitações de cada demandante.

Mas, embora ainda se distinga alguns personagens beneficiados pela solução de 2011, as forças se encontram agora em plena reconfiguração. Um confronto deste tipo até não havia sido então observado no Brasil. Nosso país foi palco de embates nos quais corporações internacionais mediram forças com as normas em vigor, como na compra da DirecTV pela Sky entre 2003 e 2006 ou da TVA pela Telefónica de 2006 a 2011. Mas, nestes momentos, o fiel da balança esteve na influência dos envolvidos de longa data com o audiovisual e a 
televisão. Precisava-se lidar com a intervenção destes grupos, e sua influência contribuiu na definição do resultado alcançado.

O caso de agora envolve um reequilíbrio de forças. As opções tendem a extremos, com duas possibilidades em jogo. A primeira se refere à eliminação integral do acordo. Abert e Abratel tenta utilizar o SeAC com este fim, tornando a norma sua ferramenta. A segunda se refere à interpretação mais próxima aos ritos procedimentais em casos desta natureza. Os termos mais racionais se atêm a compensações, como ocorre durante fusões deste tipo. A solução ainda se encontra em aberto: um resultado novo para um novo tempo. Uma certeza prevalece: no mundo, tal acordo definirá a forma das mídias; mas, no Brasil, terá um sabor especial.

\section{REFERÊNCIAS}

ABERT. Petição, Manifestação. Brasília: Associação Brasileira de Emissoras de Rádio e Televisão, 26 abr. 2017a.

ABERT. Petição, Informações. Brasília: Associação Brasileira de Emissoras de Rádio e Televisão, 12 jun. $2017 b$.

ALTHUSSER, L. A favor de Marx. Rio de Janeiro: Zahar, 1965.

ANATEL. Informe n⿳0 15/2017/SEI/CPOE/SCP. Brasília: Agência Nacional de Telecomunicações, 19 abr. 2017a. Disponível em: <http://www.telesintese.com.br/wp-content/uploads/2017/05/anatel-eatt-e-warner-area-tecnica.pdf>. Acesso em: 19 dez. 2018.

ANATEL. Parecer no 00302/2017/PFE-Anatel/PGF/AGU. Brasília: Procuradoria Federal Especializada Junto à Anatel, 4 maio 2017b. Disponível em:

<https://sei.anatel.gov.br/sei/modulos/pesquisa/md_pesq_documento_consulta_externa.php?eEPwqk1 skrd8hSlk5Z3rN4EVg9uLJqrLYJw_9INcO43zVFUHrGi5Fl7bTAmwy5wutfct-

PvMo2GbGntXqfKSU87Nm0ZZw26Pdc8yOhb9MbjI8UR1GuZQB4TSfwmahO0>. Acesso em: 2 out. 2018.

ANCINE. Instrução Normativa no 102. Brasília: Agência Nacional do Cinema, 19 jun. 2012. Disponível em: <https://www.ancine.gov.br/pt-br/legislacao/instrucoes-normativasconsolidadas/instru-o-normativa-n-102-de-19-de-junho-de-2012>. Acesso em: 9 jan. 2019.

ANCINE. Nota Técnica no 3/2017. Brasília: Agência Nacional do Cinema, 11 maio 2017. Disponível em: <http://www.telesintese.com.br/wp-content/uploads/2017/05/Nota-tecnica-Ancine-ATT-

TimeWarner.pdf>. Acesso em: 18 nov. 2018.

AT\&T. AT\&T to Acquire Time Warner. ENP Newswire, 22 out. 2016.

BERBERT, L. Cade aceita intervenção de terceiros no processo da compra da Time Warner pela AT\&T. Teletime, 3 maio 2017a. 
BERBERT, L. Abert e Abratel recorrem à Anatel para que mude posição sobre fusão Time Warner/AT\&T. Teletime, 25 jul. $2017 \mathrm{~b}$.

BERBERT, L. Abratel comemora cautelar da Anatel sobre compra da Time Warner pela AT\&T.

Teletime, 11 ago. 2017c.

BERBERT, L. Cade aprova fusão Time Warner/AT\&T com "remédios" e sem levar em conta a Lei do SeAC. Teletime, 18 out. 2017 d.

CADE. Parecer n $\mathbf{n}^{0}$ 27/2017/CGEP/PFE-CADE-CADE/PGF/AGU 12/07/2017. Brasília: Conselho Administrativo de Defesa Econômica, 12 jul. 2017. Disponível em:

$<$ https://sei.cade.gov.br/sei/modulos/pesquisa/md_pesq_documento_consulta_externa.php?DZ2uWea YicbuRZEFhBtn3BfPLlu9u7akQAh8mpB9yOsYrcdoIvdV4mbPd7DqXpHXPfWCDWUPD0TEvtXHA8JzJWXQ_H 9ySd1n971E_KP7f6HCMFb6YTAfCOOQYwJRsAX>. Acesso em: 20 nov. 2018.

DELEUZE, G. Foucault. São Paulo: Brasiliense, 1986.

FOUCAULT, M. A arqueologia do saber. Rio de Janeiro: Forense Universitária, 1969.

FOUCAULT, M. Vigiar e Punir. Petrópolis: Vozes, 1975.

GALLOWAY, A. Protocol: How Control Exists after Decentralization. Cambridge, Mass.: MIT Press, 2004.

HALL, S. Da Diáspora. Belo Horizonte: Ed. UFMG, 2003.

HUHTAMO, E.; PARIKKA, J. (EDS.). Media Archaeology: Approaches, Applications, and Implications. Berkeley: University of California Press, 2011.

KEATING, G. Netflixed: The Epic Battle for America’s Eyeballs. Nova York: Penguin, 2012.

LADEIRA, J. M. Imitação do Excesso: Televisão, Streaming e o Brasil. Rio de Janeiro: Folio Digital, 2016.

LEE, E.; KANG, C. U.S. Declines To Pursue Injunction In AT\&T Deal. The New York Times, p. B3(L), 15 jun. 2018.

LOTZ, A. The Television Will Be Revolutionized. 2nd. ed. Nova York: NYU Press, 2014.

MACHADO, A. A televisão levada a sério. São Paulo: SENAC, 2000.

MARTÍN-BARBERO, J. Dos meios às mediações: comunicação, cultura e hegemonia. Rio de Janeiro: UFRJ, 1998.

MASSUMI, B. A User's Guide to Capitalism and Schizophrenia: Deviations from Deleuze and Guattari. Cambridge, Mass: The MIT Press, 1992.

MERCED, M. J. D. LA; GELLES, D. AT\&T to Acquire DirecTV in Move to Expand Clout. The New York Times, 18 maio 2014.

MITTELL, J. Complex TV: The Poetics of Contemporary Television Storytelling. New York, NY London: NYU Press, 2015.

PARIKKA, J. What is Media Archaeology? Cambridge: Polity, 2012. 
POSSEBON, S. TV por assinatura: 20 anos de evolução. São Paulo: ABTA, 2009.

POSSEBON, S. Consolidações entre setores de mídia e telecom não podem acontecer no Brasil.

Teletime, 21 out. 2016.

VOGELSTEIN, F. Dogfight: How Apple and Google Went to War and Started a Revolution. New York: Sarah Crichton Books, 2013.

WOLK, A. Over The Top: How The Internet Is (Slowly But Surely) Changing The Television Industry. S.1.: CreateSpace Independent Publishing Platform, 2015.

WU, T. Impérios da comunicação. Rio de Janeiro: Zahar, 2012.

ZIELINSKI, S. Audiovisions: Cinema and Television as Entr'actes in History. Amsterdam: Amsterdam University Press, 1994.

\section{Original recebido em: 23 de agosto de 2019}

Aceito para publicação em: 28 de abril de 2020

João Martins Ladeira

Doutor em sociologia (Iuperj), Mestre em Comunicação (UFF). Professor do Programa de Pós-Graduação em Comunicação (UFPR).

\section{(@) $\odot \odot$}

Esta obra está licenciada com uma Licença

Creative Commons Atribuição-NãoComercial-CompartilhaIgual 4.0 Internacional 